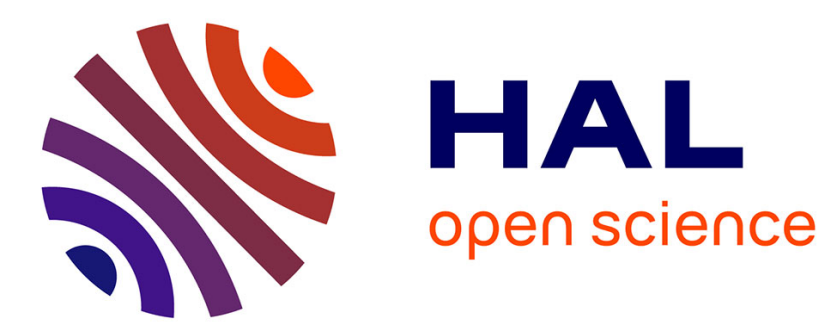

\title{
A first-order correction to minimize environmental influence in sedimentary records of relative paleointensity of the geomagnetic field
}

Alain Mazaud

\section{- To cite this version:}

Alain Mazaud. A first-order correction to minimize environmental influence in sedimentary records of relative paleointensity of the geomagnetic field. Geochemistry, Geophysics, Geosystems, 2006, 7 (7), pp.n/a-n/a. 10.1029/2006GC001257 . hal-03118229

\author{
HAL Id: hal-03118229 \\ https://hal.science/hal-03118229
}

Submitted on 20 Jul 2021

HAL is a multi-disciplinary open access archive for the deposit and dissemination of scientific research documents, whether they are published or not. The documents may come from teaching and research institutions in France or abroad, or from public or private research centers.
L'archive ouverte pluridisciplinaire HAL, est destinée au dépôt et à la diffusion de documents scientifiques de niveau recherche, publiés ou non, émanant des établissements d'enseignement et de recherche français ou étrangers, des laboratoires publics ou privés. 


\title{
A first-order correction to minimize environmental influence in sedimentary records of relative paleointensity of the geomagnetic field
}

\author{
Alain Mazaud \\ Laboratoire des Sciences du Climat et de l'Environnement, CEA-CNRS, Domaine du CNRS, F-91198 Gif-sur-Yvette, \\ France (mazaud@lsce.cnrs-gif.fr)
}

[1] We propose a simple method to minimize the residual environmental influence which may exist in paleointensity records obtained from sediments. It consists of adding, or subtracting, a fraction of the normalizer ( $\kappa, A R M$, or IRM) to the normalized intensity record, so that the corrected record exhibits fluctuations uncorrelated with those of the normalizer. This method was tested with paleointensity records obtained from two cores taken at midlatitude in the South Indian Ocean cores, eastward of the Kerguelen plateau. For each core, correction increases the correlation between the three normalized intensity records, $\mathrm{NRM} / \kappa, \mathrm{NRM} / \mathrm{ARM}$, and NRM/IRM. It also reduces the coherence between paleointensity records and bulk magnetic parameters used as normalizers. Although it has to be used with caution, this correction may improve paleointensity records by reducing nongeomagnetic influence. It can also be used to detect intervals where paleointensity may be unreliable, i.e., intervals where large differences between uncorrected and corrected records are observed, before and after correction.

Components: 3876 words, 5 figures, 4 tables.

Keywords: correction; field; geomagnetic; paleointensity; sediment.

Index Terms: 1521 Geomagnetism and Paleomagnetism: Paleointensity; 1560 Geomagnetism and Paleomagnetism: Time variations: secular and longer.

Received 30 January 2006; Revised 24 March 2006; Accepted 14 April 2006; Published 7 July 2006.

Mazaud, A. (2006), A first-order correction to minimize environmental influence in sedimentary records of relative paleointensity of the geomagnetic field, Geochem. Geophys. Geosyst., 7, Q07002, doi:10.1029/2006GC001257.

\section{Introduction}

[2] Geomagnetic field paleointensity records are widely used to better understand the core dynamics and how the geomagnetic field is generated, to intercorrelate sediments deposited in environmental contexts [Guyodo and Valet, 1996, 1999; Laj et al., 2000, 2004; Stoner et al., 2000], and sediments with ice [Wagner et al., 2001]. Because Earth's magnetic field partially deflects incoming cosmic rays, paleointensity records are also of great inter- est for evaluating the past abundance of radiocarbon in the different natural reservoirs, and therefore in 14-C age determinations [Elsasser et al., 1956; Mazaud et al., 1991; Laj et al., 2002]. Consequently, obtaining high-resolution records of past geomagnetic field intensity has become one of the major objectives of the paleomagnetists for the last 10 years. Efforts were put on sediments, because they can provide continuous records, despite only relative changes of past field intensity are obtained. In principles, paleointensity records are obtained 
from sediments by dividing the intensity of the Natural Remanent Magnetization (NRM) left after removal of any viscous component by a normalizer, which represents the variability in the "magnetization potential" of the sediments [Johnson et al., 1948]. The Anhysteretic Remanent Magnetization (ARM), the Isothermal Remanent Magnetization (IRM), and the low field susceptibility ( $\kappa)$ are used as normalizers [Johnson et al., 1975; Hartl et al., 1993; Harrison, 1966]. $\kappa$ is determined by the amount, nature and size of the magnetic grains inside the sediment, but also by the paramagnetic fraction of the sediment, so that its use may be more delicate. Thus ARM and IRM, which depend solely on the ferro/ferri magnetic phase, are usually preferred to $\kappa$. Reliable paleointensity records can be obtained only if the magnetic characteristics of the natural field recorder exhibit limited changes down core, and criteria were proposed to select sediments suitable for paleointensity determination [King et al., 1983; Tauxe, 1993]. The NRM must be carried by stable magnetite preferably in the grain size range of $1-$ $15 \mu \mathrm{m}$, concentration variations of more than an order of magnitude should be avoided. However, our knowledge of the processes responsible for the magnetization of pelagic sediments is far from being complete, and a number of nongeomagnetic phenomena can affect the magnetic record in sediment, such as changes in grain size and mineralogy variations caused by climatic and environmental variations, and/or diagenetic processes in the sedimentary column [Tarduno and Wilkinson, 1996; Schwartz et al., 1996; Smirnov and Tarduno, 2000]. Consequently, it is delicate to assess the exact accuracy of normalized records, and classical tests consist of comparing the records obtained with the 3 normalizers, which should give consistent results, and of calculating the coherence function between the normalized intensity record and the normalized, in order to detect environmental contamination [Tauxe, 1993; Tauxe and $W u, 1990]$. Here we propose to reduce the non geomagnetic contribution which may exist in normalized intensity records by adding, or subtracting, a fraction of the normalizer, so that the corrected paleointensity and the normalizer records exhibit uncorrelated fluctuations.

\section{Methodology}

[3] Normalization of the cleaned NRM intensity by $\kappa$, ARM, or IRM, is classically used to correct for the variation in the amount of magnetic remanence
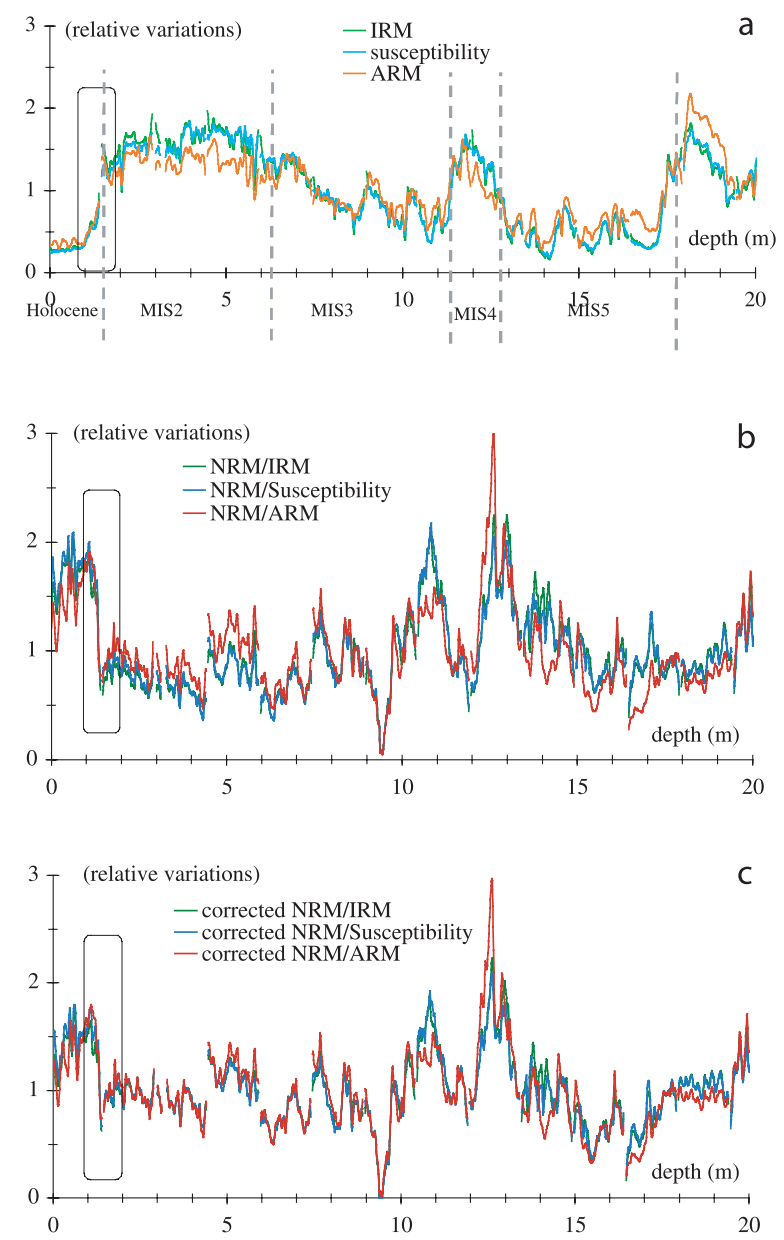

Figure 1. (a) ARM, IRM, and $\kappa$ records of core MD94-103 versus depth. Marine Isotopic Stages (MIS) boundaries are indicated. (b) NRM/ARM, NRM/IRM, and NRM/ $\kappa$ records before correction. (c) Paleointensity records after correction. Deglaciation is indicated by a rectangle.

carriers in the sediments. In the case of an ideal sediment, the normalizer activates the same grains that carry the NRM [Levi and Banerjee, 1976]. Taking ARM as the normalizer in the formula below, one can write

$$
\operatorname{IntN}(\mathrm{z})=\operatorname{NRM}(\mathrm{z}) / \operatorname{ARM}(\mathrm{z})=\mathrm{a} \mathrm{B}(\mathrm{z}),
$$

where $\mathrm{B}(\mathrm{z})$ is the actual paleofield intensity to be determined, $z$ is the depth down core, $\operatorname{IntN}(\mathrm{z})$ is the normalized intensity, $\operatorname{ARM}(z)$ is the ARM value at depth $\mathrm{z}$, and parameter a is a proportionality factor, not determined because sediments provide only relative paleointensities.

[4] In the case of a nonideal sediment, the normalized intensity $\mathrm{IntN}$ is also affected by 
Table 1a. Correlation Coefficients Obtained Before Correction of Core MD94-103 Paleointensity Records ${ }^{\mathrm{a}}$

\begin{tabular}{lcccc}
\hline MD94-103 & NRM/ARM & NRM/IRM & NRM/k & $\begin{array}{c}\text { CC With } \\
\text { Normalizer }\end{array}$ \\
\hline NRM/ARM & 1 & 0.81 & 0.80 & -0.28 \\
NRM/IRM & & 1 & 0.98 & -0.55 \\
NRM/k & & & 1 & -0.54 \\
\hline
\end{tabular}

${ }^{a}$ Correlation coefficients $(\mathrm{CCs})$ are calculated between the different paleointensity records and also between the paleointensity records and their normalizers.

nongeomagnetic contribution due to depositional and diagenetic processes in the sediment. Here, it is assumed here that this contribution can be related to the fluctuations of the bulk sediment magnetic parameter normalizer ( $\kappa$, ARM, or IRM), which tracks the variations of the magnetic material in the sediment. If this nongeomagnetic contribution is small, a linear approximation can be considered, then the nongeomagnetic contribution to be added to equation (1) can be thus expressed as

$$
\mathrm{e}(\operatorname{ARM}(\mathrm{z})-\mathrm{MARM})
$$

where MARM is the mean value of $\operatorname{ARM}(z)$ measured down core. In this linear approach, the residual nongeomagnetic contribution is therefore maximal when ARM exhibits a maximal deviation from its mean value. When this nongeomagnetic term is considered, equation (1) becomes

$$
\begin{aligned}
\operatorname{IntN}(\mathrm{z}) & =\mathrm{NRM}(\mathrm{z}) / \operatorname{ARM}(\mathrm{z}) \\
& =\mathrm{aB}(\mathrm{z})+\mathrm{e}(\operatorname{ARM}(\mathrm{z})-\operatorname{MARM}),
\end{aligned}
$$

where e is a proportionality factor, to be determined. In the ideal case, e equals zero, and the normalized intensity is strictly proportional to the paleofield intensity (1). In cases where a nongeomagnetic contribution does exist, e is not equal to zero. As a consequence, IntN is not proportional to the paleofield, because of the presence of this nongeomagnetic term.
[5] Finally, (3) can be rewritten as

$$
\mathrm{B}(\mathrm{z})=(1 / \mathrm{a})\{\operatorname{NRM}(\mathrm{z}) / \operatorname{ARM}(\mathrm{z})-\mathrm{e}(\operatorname{ARM}(\mathrm{z})-\operatorname{MARM})\} .
$$

Since $\mathrm{B}(\mathrm{z})$ is the actual paleofield, the "correct" (or corrected) relative paleointensity record, IntCorr, is given by

$$
\begin{aligned}
\operatorname{IntCorr}(\mathrm{z}) & =\mathrm{aB}(\mathrm{z}) \\
& =\mathrm{NRM}(\mathrm{z}) / \operatorname{ARM}(\mathrm{z})-\mathrm{e}(\operatorname{ARM}(\mathrm{z})-\operatorname{MARM}) .
\end{aligned}
$$

Parameter e is the unknown parameter. Here, e is determined by an iterative trial and error process, so that the fluctuations of the corrected paleointensity record, IntCorr, and the fluctuations of normalizer exhibit a correlation coefficient (CC) lower than 0.05. It is assumed that the geomagnetic field intensity has varied independently from magnetic mineral deposition, a commonly accepted hypothesis.

\section{Examples}

[6] The method was tested with two cores taken from the South Indian Ocean, eastward of the Kerguelen plateau. Both cores are located at latitudes around $45^{\circ}$ South along the southern flank of the South Indian Ocean ridge. They were taken in a zone where a large thickness of magnetite-rich sediment eroded from the Kerguelen volcanic plateau and transported by the Antarctic Circum Current (ACC) accumulated [Dezileau et al., 2000; Mazaud et al., 2002]. Core MD94-103 $\left(45^{\circ} 35^{\prime} \mathrm{S} ; 86^{\circ} 31^{\prime} \mathrm{E}\right)$ was taken by the Research vessel Marion-Dufresne during a PACIMA cruise at a depth of $3559 \mathrm{~m}$. It covers the last climatic cycle. NRM, ARM and IRM records [Mazaud et al., 2002] were obtained at the LSCE with uchannel technique using small access $2 \mathrm{G}$ passthrough magnetometers [Weeks et al., 1993]. High-resolution bulk magnetic susceptibility $(\kappa)$ was measured using a Bartington sensor loop in line with a track system also designed for $\mathrm{u}$ -

Table 1b. Correlation Coefficients Obtained After Correction of Core MD94-103 Paleointensity Records ${ }^{\mathrm{a}}$

\begin{tabular}{lcccc}
\hline \multicolumn{1}{c}{ MD94-103 } & IntCorr(ARM) & IntCorr(IRM) & IntCorr(k) & CC With Normalizer \\
\hline IntCorr(ARM) & 1 & 0.91 & 0.90 & -0.045 \\
IntCorr(IRM) & & 1 & 0.98 & -0.042 \\
IntCorr(k) & & 1 & -0.041 \\
\hline
\end{tabular}

\footnotetext{
${ }^{\mathrm{a}} \mathrm{CCs}$ are calculated between the different paleointensity records and also between the paleointensity records and their normalizers.
} 

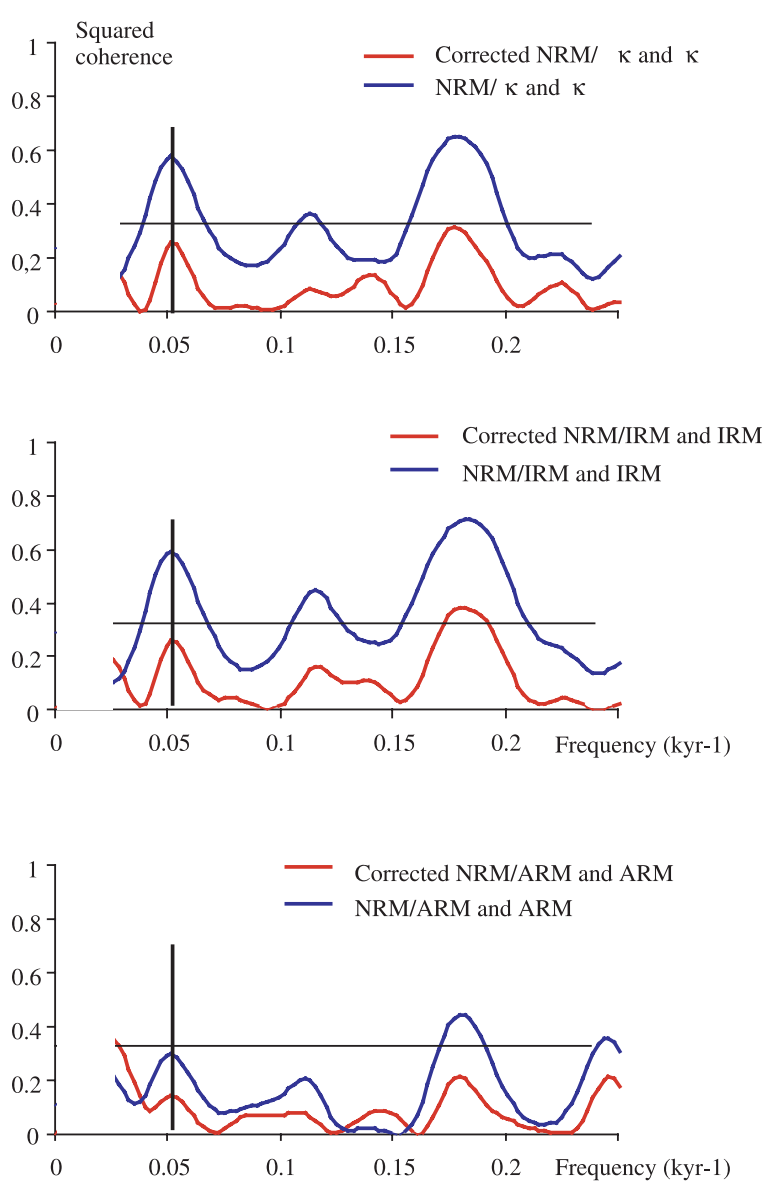

Figure 2. Squared coherence obtained for core MD94103 between paleointensity records and bulk magnetic records used as normalizers, before and after correction. Confidence levels are indicated by horizontal lines. 19 kyr periodicity is indicated by a vertical line.

channels. Like several other cores from this region eastward of the Kerguelen plateau, $\kappa$, ARM, and IRM exhibit higher values during Marine Isotopic Stages (MIS) 2, 4 and 6 than during the Holocene and MIS 5 [Dezileau et al., 2000; Mazaud et al., 2002]. It was interpreted as reflecting a stronger deposition of magnetic grains during MIS 2, 4, and 6 [Dezileau et al., 2000]. Magnetic mineralogy analyses indicated pseudo mono-domain (titano)magnetite grains as dominant carrier of the NRM, with Curie temperature close to that of magnetite and hysteresis determinations indicate limited grain size change, within accepted criteria for paleointensity determinations [Mazaud et al., 2002]. This core provides a record of the Laschamp geomagnetic event in the South hemisphere [Mazaud et al., 2002; Laj et al., 2006], and a geomagnetic correlation to NAPIS-75, a paleointensity record obtained from the North Atlantic [Laj et al., 2000] allowed to place core MD94-103 onto the Greenland GISP2 age model in the 30-50 kyr B.P.
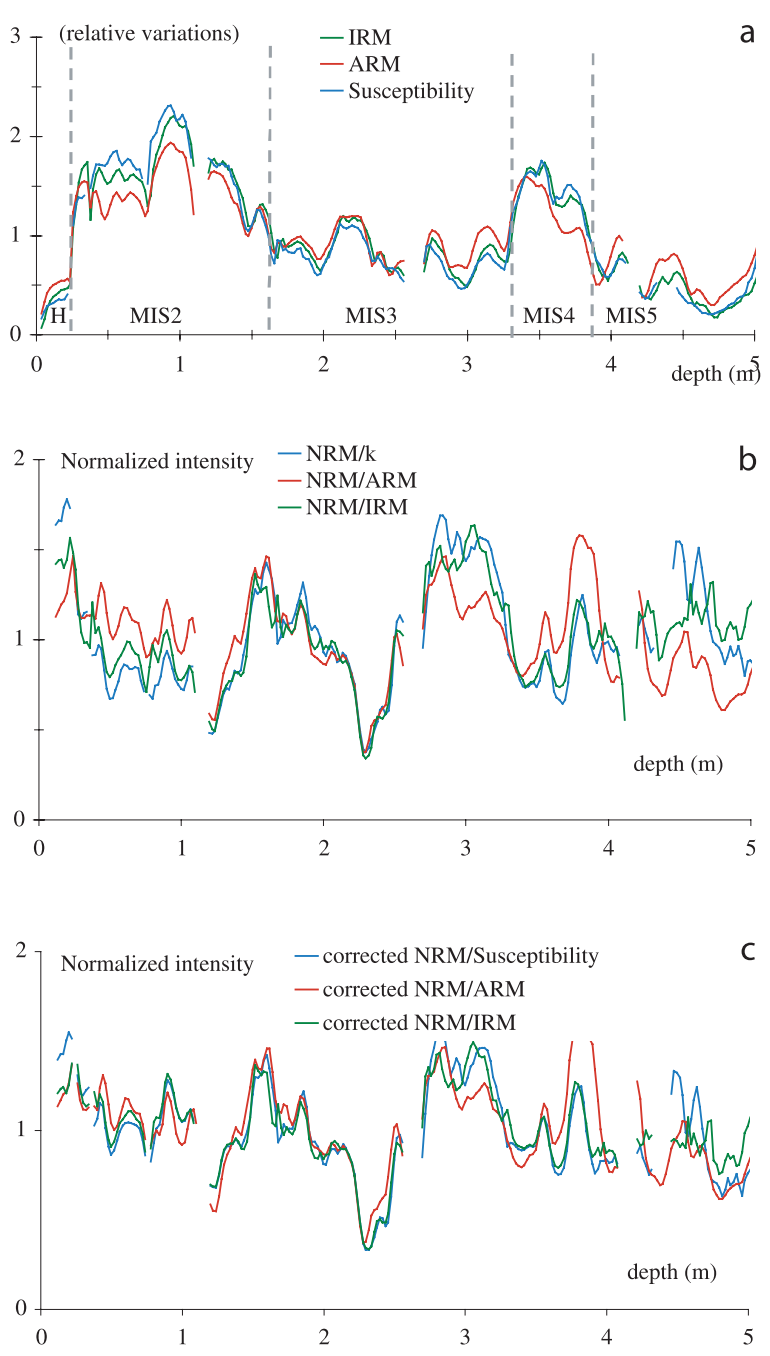

Figure 3. (a) ARM, IRM, and $\kappa$ records of core MD88-769. Marine Isotopic Stages (MIS) boundaries are also indicated. (b) NRM/ARM, NRM/IRM, and $\mathrm{NRM} / \kappa$ records before correction. (c) Paleointensity records after correction.

interval [Mazaud et al., 2002]. ARM, IRM, and $\kappa$ exhibit similar variations, with abrupt change at the time of the last deglaciation (Figure 1a). NRM/ ARM, NRM/IRM, and NRM/ $\kappa$ also exhibit an abrupt change concomitant to that of the bulk magnetic parameters, which makes plausible the

Table 2a. Same as Table 1a, but With Core MD88-769 CC With

MD88-769 NRM/ARM NRM/IRM NRM/k Normalizer

\begin{tabular}{lcccc}
\hline NRM/ARM & 1 & 0.64 & 0.72 & -0.01 \\
NRM/IRM & & 1 & 0.92 & -0.43 \\
NRM/k & & & 1 & -0.5 \\
\hline
\end{tabular}


Table 2b. Same as Table $1 \mathrm{~b}$, but With Core MD88-769

\begin{tabular}{lcccc}
\hline MD88-769 & IntCorr(ARM) & IntCorr(IRM) & IntCorr(k) & CC With Normalizer \\
\hline IntCorr(ARM) & 1 & 0.80 & 0.90 & -0.01 \\
IntCorr(IRM) & & 1 & 0.93 & 0.03 \\
IntCorr(k) & & 1 & -0.026 \\
\hline
\end{tabular}

idea of some environmental influence in the records of normalized intensity.

[7] The above correction method was successively applied to the three normalized intensity records, NRM/ARM, NRM/IRM, and NRM/ $/$. Corrected records (Figure 1c) do not largely differ from uncorrected ones (Figure 1b). However, the correction significantly reduces the amplitude of the variation at the deglaciation (Figure 1c). As illustrated by Figure 1 and by the correlation coefficients shown in Tables $1 \mathrm{a}$ and $1 \mathrm{~b}$, the correction has improved the consistency between the three paleointensity records obtained with the 3 normalizers. Coherence was also calculated between paleointensity and normalizer, before and after correction (Figure 2). To obtain temporal spectra, core MD94-103 was aged considering radiocarbon age determinations for the past $30 \mathrm{kyr}$ B.P. [Sicre et al., 2005] and a geomagnetic correlation to NAPIS-75 in the 30-50 kyr B.P. interval [Mazaud et al., 2002]. It is observed that the correction significantly reduces the coherence between normalized intensity records and normalizer, in particular at Earth's precession periodicity (Figure 2). Finally, the corrected NRM/ARM record is compared to GLOPIS-75 [Laj et al., 2004]. Despite differences at deglaciation time and around $25 \mathrm{kyr}$ B.P., this record resembles the GLOPIS-75 stack, with a marked low corresponding to the Laschamp geomagnetic event (Figure 5a).

[8] The second core, MD88-769, was taken in the same sedimentary formation, but eastward from MD94-103 during the ASPARA cruise of the R.V Marion-Dufresne. NRM, ARM and $\kappa$ were also measured at the LSCE with u-channel technique. MIS were clearly identified, and the bulk magnetic parameters exhibits variations similar to those of core MD 94-103 (Figure 3a). However, core MD88-769 is located at a greater distance from the erosion sources, the Crozet-Kerguelen plateau, than core MD94-103. Consequently, core MD88-769 is characterized by a sedimentation rate of about $6.5 \mathrm{~cm} / \mathrm{kyr}$, lower than that of core MD94-103, of about $20 \mathrm{~cm} / \mathrm{kyr}$ [Mazaud et al., 2002]. As for core MD94-103, above correction was successively applied to the three normalized intensity records, NRM/ARM, NRM/IRM, and
$\mathrm{NRM} / \kappa$. Figures $3 \mathrm{~b}$ and $3 \mathrm{c}$ show the relative intensity profiles obtained before and after correction, respectively. A better consistency between the 3 normalized relative intensity profiles is obtained after correction (Figure 3). Correction increases the correlation between normalized intensity records and normalizers (Tables $2 \mathrm{a}$ and $2 \mathrm{~b}$ ). NRM/ARM
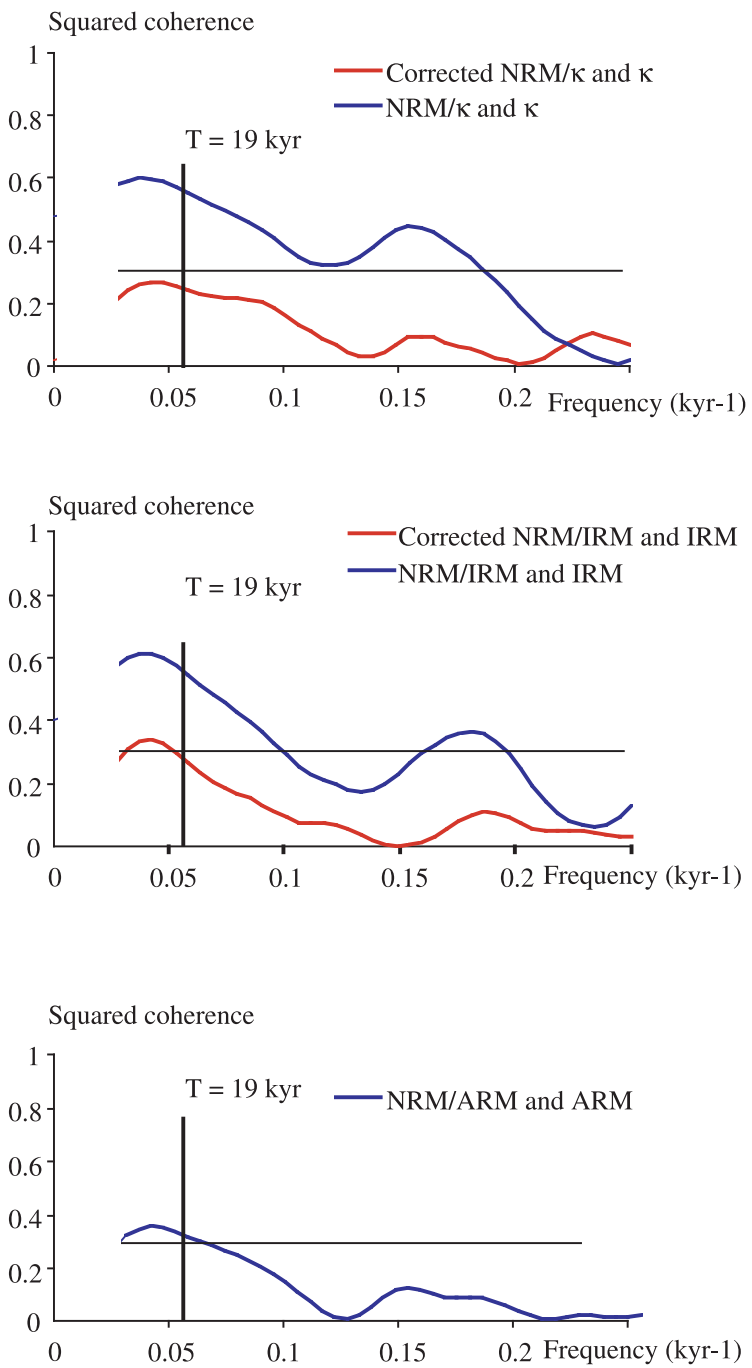

Figure 4. Squared coherence obtained for core MD88769 between paleointensity records and bulk magnetic records used as normalizers, before and after correction. Confidence levels are indicated by horizontal lines. $19 \mathrm{kyr}$ periodicity is indicated by a vertical line. No correction was necessary for the NRM/ARM record (see text and Tables $2 \mathrm{a}$ and $2 \mathrm{~b}$ ). 
GLOPIS-75

a

(VADM 10^22 $\mathrm{Am}^{\wedge} 2$ )

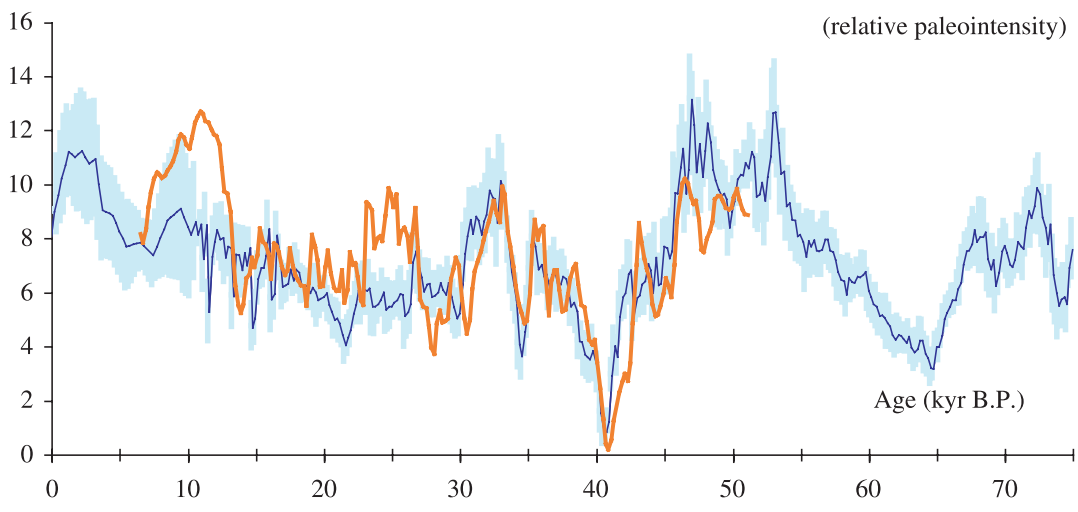

GLOPIS-75

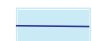

b

(VADM 10^22 $\left.\mathrm{Am}^{\wedge} 2\right)$

- MD88-769

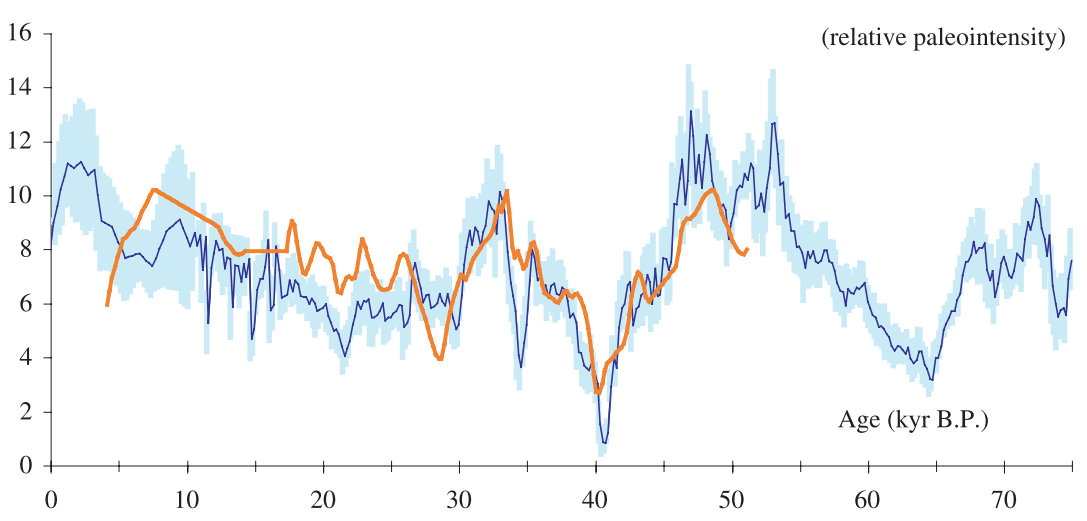

Figure 5. (a) Comparison between the paleointensity record of core MD94-103 (corrected NRM/ARM) and the GLOPIS-75 stack. (b) Comparison between the paleointensity record of core MD88-769 (NRM/ARM) and the GLOPIS-75 stack.

record is not changed (CC between NRM/ARM and ARM is below 0.05 before correction; see Tables $2 \mathrm{a}$ and $2 \mathrm{~b}$ ), but NRM/IRM and NRM/ records are corrected so that they closely resemble the NRM/ARM record. Coherence spectra between normalized intensities and normalizers were calculated, before and after correction (Figure 4). Age model was derived for this core by correlating its susceptibility signal to the susceptibility signal of core MD94-103. The correction reduces the coherence between NRM/IRM and IRM, and between $\mathrm{NRM} / \kappa$ and $\kappa$. MD88-769 record resembles GLOPIS-75 record (Figure 5b). A less marked minimum in intensity is visible at the Laschamp geomagnetic event. Core MD88-769, however, has a sedimentation rate lower than that of cores used in the GLOPIS-75 stack, so that its geomagnetic signal is more smoothed than the GLOPIS-75 stack.

\section{Discussion and Conclusion}

[9] We have tried to reduce the nongeomagnetic influence in normalized intensity records by considering a linear correction, in which a fraction of the normalizer is added, or subtracted, to the normalized intensity record. It can be seen as a principal component analysis, in which the corrected record is a linear combination of two initial records, the normalized intensity and the normalizer. In the two examples discussed above, correction reduces the coherence between paleointensity 
records and their normalizers. It also improves the correlation between the paleointensity records obtained with the different normalizers. Because $\kappa$, ARM, and IRM differently record magnetic mineralogy and grain size changes, improvement in correlation between NRM/ARM, NRM/IRM, and $\mathrm{NRM} / \kappa$, is a strong indication that the correction was able to reduce the nongeomagnetic contribution remaining in each normalized intensity record, so that the three corrected records converge toward the actual (relative) paleointensity of the geomagnetic field.

[10] The proposed correction method, however, has to be used with caution. Only one parameter, $\mathrm{e}$, is adjusted in order to reduce the correlation coefficient (CC) between the paleointensity record and the normalizer. $\mathrm{CC}$ is an indicator of the global correlation and does not document the spectral distribution of the coherence. Thus it is strongly recommended to calculate the coherence function between the normalizer and the paleointensity, before and after correction in order to check how the coherence is modified at the different frequencies by the proposed correction. Because a linear approximation is adopted for the correction, it can be only used for cores with limited changes in mineralogy and grain size, thus fitting selection criteria for paleointensity determinations. Also, because of its simplicity, the proposed correction cannot be used for artifacts like those involving convolution, such as smoothing and delayed remanence acquisition. Complication also occurs if the mineralogy exhibits complex variations, so that different corrections have to be envisaged for different depth intervals. Also, the time interval over which the correlations are calculated should be large enough, so that independence between climatic and geomagnetic fluctuations is statistically realized. For instance, in the case of core MD94-103, a calculation restricted to the last deglaciation would led to overcorrection, in which any trend in paleointensity the during the deglaciation would be eliminated. In a conservative approach, this method can be also used to detect intervals where relative paleointensity records may be unreliable, i.e., intervals where large differences between uncorrected and corrected records are observed, and/or intervals where the correction fails to reconcile the 3 normalized records, as this is for example the case for core MD88-769 in the 3.8-5.0 m interval. Comparisons with other methods will be of great interest, such as that of Brachfeld and Banerjee [2000] based on the use of grain size estimates and of Hofmann et al.
[2002, 2005], in which environmental influence is reduced by minimizing the differences between several paleointensity records obtained from a limited geographic area, so that they recorded the same geomagnetic changes.

\section{Acknowledgments}

[11] This work was supported by the CNRS and the CEA. The author thanks K. Fabian and Daniela Hofmann for discussions, C. Laj and Yohan Guyodo for discussions and suggestions, and reviewers for helpful comments. LSCE contribution 1910

\section{References}

Brachfeld, S. A., and S. K. Banerjee (2000), A new highresolution geomagnetic relative paleointensity record from the North American Holocene: A comparison of sedimentary and absolute intensity data, J. Geophys. Res., 105, 821-834.

Dezileau, L., G. Bareille, J. L. Reyss, and F. Lemoine (2000), Evidence for strong sediment redistribution by bottom currents along the southeast Indian ridge, Deep Sea Res., Part 1, 47, 1899-1936.

Elsasser, W. M., E. P. Ney, and J. R. Winckler (1956), Cosmic ray intensity and geomagnetism, Nature, 178, 1226-1227.

Guyodo, Y., and J. P. Valet (1996), Relative variations in geomagnetic intensity from sedimentary records, Earth Planet. Sci. Lett., 143, 23-26.

Guyodo, Y., and J. P. Valet (1999), Global changes in intensity of the Earth's magnetic field during the past $800 \mathrm{kyr}$, Nature, $399,249-252$.

Harrison, C. G. A. (1966), The paleomagnetism of deep-sea sediments, J. Geophys. Res., 71, 3033-3043.

Hartl, P., L. Tauxe, and C. Constable (1993), Early Oligocene geomagnetic field behaviour from Deep Sea Drilling Project 522, J. Geophys. Res., 98(B11), 19,649-19,655.

Hofmann, D., K. Fabian, C. Franke, T. von Dobeneck, and F. Schmieder (2002), Investigation of six relative geomagnetic paleointensity records from the subtropical and subantarctic South Atlantic with respect to lithological influences, Q. Geofis., 26, 57-59.

Hofmann, D., K. Fabian, F. Schmieder, B. Donner, and U. Bleil (2005), A stratigraphic network across the subtropical front in the central South Atlantic: Multi-parameter correlation of magnetic susceptibility, density, X-ray, fluorescence and $\delta^{18} \mathrm{O}$ records, Earth Planet. Sci. Lett., 240, 694-709.

Johnson, E. A., T. Murphy, and O. W. Torreson (1948), Prehistory of the Earth's magnetic field, J. Geophys. Res., 53, 349-372.

Johnson, H. P., W. Lowrie, and D. V. Kent (1975), Stability of anhysteretic remanent magnetization in fine and coarse magnetite and maghemite particles, Geophys. J. R. Astron. Soc., $41,1-10$.

King, J. W., S. K. Banerjee, and J. M. Marvin (1983), A new rock-magnetic approach to selecting sediments for geomagnetic paleointensity studies: Application to paleointensity for the last 4000 years, J. Geophys. Res., 88, 5911-5921.

Laj, C., C. Kissel, A. Mazaud, J. E. T. Channell, and J. Beer (2000), North Atlantic paleointensity stack since $75 \mathrm{ka}$ (NAPIS-75) and the duration of the Laschamp event., Philos. Trans. R. Soc. London, Ser. A, 358, 1009-1025. 
Laj, C., C. Kissel, A. Mazaud, E. Michel, R. Muscheler, and J. Beer (2002), Geomagnetic field intensity, North Atlantic deep water circulation and atmospheric $\Delta^{14} \mathrm{C}$ during the last 50 kyr, Earth Planet. Sci. Lett., 200, 179-192.

Laj, C., C. Kissel, and J. Beer (2004), High-resolution global paleointensity stack since $75 \mathrm{kyr}$ (GLOPIS-75) calibrated to absolute values, in Timescales of the Paleomagnetic Field, Geophys. Monogr. Ser., vol. 145, pp. 225-265, AGU, Washington, D. C.

Laj, C., C. Kissel, and A. P. Roberts (2006), Geomagnetic field behavior during the Iceland Basin and Laschamp geomagnetic excursions: A simple transitional field geometry?, Geochem. Geophys. Geosyst., 7, Q03004, doi:10.1029/ 2005GC001122.

Levi, S., and S. K. Banerjee (1976), On the possibility of obtaining relative paleointensities from lake sediments, Earth Planet. Sci. Lett., 29, 219-226.

Mazaud, A., C. Laj, E. Bard, and E. Tric (1991), Geomagnetic field control of ${ }^{14} \mathrm{C}$ production over the last $80 \mathrm{ky}$ : Implications for the radiocarbon timescale, Geophys. Res. Lett., 18, $1885-1888$.

Mazaud, A., M. A. Sicre, U. Ezat, J. J. Pichon, J. Duprat, C. Laj, C. Kissel, L. Beaufort, E. Michel, and J. L. Turon (2002), Geomagnetic assisted stratigraphy and SST changes in core MD94-103 (southern Indian Ocean): Possible implications for North-South climatic relationships around H4, Earth Planet. Sci. Lett., 20, 159-170.

Schwartz, M., S. P. Lund, and T. C. Johnson (1996), Environmental factors as complicating influences in the recovery of quantitative geomagnetic field paleointensity estimates from sediments, Geophys. Res. Lett., 23, 2693-2696.

Sicre, M. A., L. Labeyrie, U. Ezat, J. Duprat, J. L. Turon, S. Schmidt, E. Michel, and A. Mazaud (2005), Mid-latitude southern Indian Ocean response to Northern Hemisphere Heinrich events, Earth Planet. Sci. Lett., 240, 724-731.

Smirnov, A. V., and J. A. Tarduno (2000), Low-temperature magnetic properties of pelagic sediments (Ocean Drilling Program Site 805C): Tracers of maghemitization and magnetic mineral deposition, J. Geophys. Res., 105, 16,45716,471 .

Stoner, J. S., J. E. T. Channell, C. Hillaire-Marcel, and C. Kissel (2000), Geomagnetic paleointensity and environmental record from Labrador Sea Core MD95-2024: Global marine sediment and ice-core chronostratigraphy for the last 110 kyr, Earth Planet. Sci. Lett., 183, 161-177.

Tarduno, J. A., and S. L. Wilkinson (1996), Non-steady state magnetic mineral reduction, chemical lock-in, and delayed remanence acquisition in pelagic sediments, Earth Planet. Sci. Lett., 144, 315-326.

Tauxe, L. (1993), Sedimentary records of relative paleointensity of the geomagnetic field: Theory and practice, Rev. Geophys., 31, 319-354.

Tauxe, L., and G. Wu (1990), Normalized remanence in sediments of the western equatorial Pacific: Relative paleointensity of the geomagnetic field, J. Geophys. Res., 95, 12,33712,350 .

Wagner, G., C. Laj, J. Beer, C. Kissel, R. Muscheler, J. Mazarik, and H. A. Synal (2001), Reconstruction of the paleoprecipitation rate of central Greenland during the last $75 \mathrm{kyr}$ using the cosmogenic radionuclides $36-\mathrm{Cl}$ and $10-\mathrm{Be}$ and geomagnetic field intensity data, Earth Planet. Sci. Lett., 193, 515-521.

Weeks, R., C. Laj, L. Endignoux, M. Fuller, A. Roberts, R. Manganne, E. Blanchard, and W. Goree (1993), Improvements in long core measurements techniques: Applications in palaeomagnetism and palaeoceanography, Geophys. J. Int., 114, 651-662. 